\title{
Contribution to the preservation of healthy coastal ecosystems
}

\author{
J. S. Antunes do Carmo ${ }^{1}$, J. L. S. Pinho ${ }^{2}$ \& J. M. P. Vieira ${ }^{2}$ \\ ${ }^{1} I M A R$, Department of Civil Engineering, \\ University of Coimbra, Portugal \\ ${ }^{2}$ Department of Civil Engineering, University of Minho, Portugal
}

\section{Abstract}

The release of pollutants into coastal zones from municipal and/or industrial drainage systems is a problem with a considerable environmental impact. In order to minimize the contamination of coastal waters in certain places (e.g., along beaches and in aquacultures), solutions based on the construction of submarine sewer outfalls have been proposed. In order to ascertain the optimal conditions for the release of an emissary, in particular the place of release, it is necessary to characterize the hydrodynamic transport processes that govern the evolution and mixture of pollutants in the area of interest. Circulation in the coastal zone is complicated, given that it is determined by a set of forcing mechanisms of diverse origins (meteorological, astronomical, large-scale ocean circulation, etc.) that endow it with a considerable space-time variation. Wastewater plume behaviour and characteristics depend both on the receiving water conditions and on the discharge characteristics. Accordingly, the implementation of a submarine outfall system requires a prior study of the site where the outfall is to be constructed, in order to achieve optimal rates of dilution of the pollutants released to the environment. Mathematical modelling appears to be a very useful tool for coastal zone environmental management either for continuous monitoring analysis or in accidental ecosystem rupture. This work presents some results and conclusions of two case studies. The first is a study of the pollutant cloud released at the São Jacinto submarine sewer outfall, located about $3 \mathrm{~km}$ offshore and $3 \mathrm{~km}$ north of an important coastal lagoon (NW Portugal). The main focus of this study was to establish the hydrodynamic conditions in which the pollutant release might affect the coastline (principally the existing beaches and lagoon). The second case presents some hydrodynamic results and water quality aspects of the Ria de Arosa (NW Spain), and also includes an assessment of the environmental impact of wastewater discharges from nine submarine outfalls considered in the sanitation plan of this bay. Results of faecal matter concentration distribution were used in the discussion on the outfall discharges' impact on the natural water system for different hydrodynamic scenarios. In both cases, 3D numerical models were used.

Keywords: coastal pollution, estuaries and coastal bays, submarine outfalls, numerical modelling. 


\section{Introduction}

The sea is often viewed as a convenient place to dump waste, considered the ideal territory, capable of absorbing almost unlimited quantities of pollutants. Disposal standards at sea are lower than on land, and far harder to monitor. Furthermore, strategic planning is necessary for the implementation of a sewage system, as the availability or non-availability of such facilities can unleash or restrain coastal land development. Planning should be concerned more with the availability or capacity of a coastal site to accept sewage, rather than the actual amount to be discharged (Carter [1]).

Residual water plume behaviour and characteristics depend both on the receiving water conditions and on the discharge characteristics (Jirka et al. [2]). In relation to the first, the geometry of the water body and the dynamic conditions (receiving waters' currents and density distribution in the water column) are of interest. For the second, the mixture conditions, the geometry and type of the submarine outfall diffusers, the waste water discharge flow, the water velocity at the submarine outfall diffusers and the wastewater density are significant factors (Ramos et al. [3]).

In principle, the best results are achieved by treating sewage onshore before disposal, particularly where discharge is likely to be into a relatively sheltered environment. Without any doubt, all effluents, especially industrial effluents, must be subjected to primary (screening and sedimentation), secondary (biological oxidation of organic matter) and even tertiary (nutrient removal, especially nitrates and phosphates) treatment. In particular, the reduction of BOD and nutrient contents can have a profound effect on coastal-water quality (Carter [1]).

In order to ascertain the optimal conditions for the release of an emissary, in particular the place of release, it is necessary to characterize the hydrodynamic transport processes that govern the evolution and mixture of pollutants in the area of interest. Circulation in the coastal zone is complicated, given that it determined by a set of forcing mechanisms of diverse origins (meteorological, astronomical, large-scale ocean circulation, etc.) that endow it with a considerable space-time variation.

The fate of pollutants and their ultimate impact on biota is affected by the mechanisms of advection, turbulent diffusion and dispersion, which implicitly control a number of other important physicochemical and biological processes. The dynamics of the flow field, as well as the transport and ultimate fate of aquatic pollutants, may be described by means of the Navier-Stokes equations, the equation of continuity and the mass balance equation for pollutants.

A major effort has been made over recent decades to integrate hydrodynamic and water quality models for coastal waters studies. In these natural systems, correct simulation of the circulation patterns and the biogeochemical processes, using mathematical models, is a very powerful method that greatly enhances the decision support tools used for water resources management. 
Numerical models are also important instruments in the research into the basic processes that occur in a given region. Such models currently play an important role in the study of environmental problems of this nature.

Estuarine dynamics is generally quantified by the two-dimensional SaintVenant equations system. For vertically well-mixed estuaries, this one-layer model can adequately describe the flow characteristics, since it implicitly assumes a uniform velocity distribution in the water-column. For vertically stratified estuaries, flow dynamics must be treated by means of, at least, a two-layer system.

In the last twenty-five years, three-dimensional numerical models have mainly been developed in order to describe coastal ocean circulation. These models have extended the two-dimensional vertically integrated models to include vertical structure. As it has been shown in a number of works, the time evolution of a cloud of pollutants released from a sewer outfall is highly dependent on the vertical structure of the density and velocity fields that arise from the complex coastal circulation.

The ROMS (Regional Oceanographic Modelling System) (Song and Haidvogel [4]) and POM-UMQ (Pinho [5]), which are both 3D models, were used to obtain the numerical results presented in this work.

\section{Coastal water pollution}

As a consequence of changes in human habits and political measures implemented in the last few decades, coastal zones are nowadays very attractive regions for human settlement, but anthropogenic activities have significant environmental impacts on these sensitive natural systems. The approach to water management should be dictated by public safety, economic and environmental considerations.

From the above, it can be also concluded that coastal waters are at greater risk of being polluted than the open ocean for two reasons: (1) More pollution is dumped into coastal waters than into the open ocean, and (2) coastal waters are not as well circulated as the open ocean. Many of the concerns of pollution are therefore focused on coastal waters.

A sound understanding of the sources, transport mechanisms, storage facilities, and ultimate fate of polluting agents is essential for the proper management of a coastal ecosystem. After entering the systems, nutrients, trace metals and toxic compounds are transported by the advective motion of water and spread by turbulent mixing and molecular diffusion. Chemicals can then be found either in a dissolved state or attached to the surface of fine particles. These fine particles remain in suspension for a long while until, under low energy conditions, they settle on the bottom sediments.

During their transport or storage, pollutants can react and change their physical characteristics and chemical composition. The behaviour and transformation of pollutants depend on their physicochemical parameters and those of the ambient fluid medium, and on the hydrodynamic features of the flow. 
Five major problems arise from the discharge of sewage into coastal waters. These are associated with disease, deoxygenation, enrichment, toxicity and aesthetics. Enrichment of coastal ecosystems by nutrients (mainly nitrates and phosphates) in raw sewage may cause eutrophication, perhaps engendering short-term algal blooms or oxygen deficits, and longer-term changes in species composition, diversity and abundance. Toxic wastes often enter sewage systems by inadvertent or clandestine means (Carter [1]).

The release of pollutants from municipal and/or industrial drainage systems into the coastal zone, is a real-world problem with a considerable environmental impact. In order to minimize the contamination of coastal waters in certain places (e.g., on beaches and in aquacultures), solutions based on the construction of submarine sewer outfalls have been proposed. The predominant method of sewage disposal in many coastal communities nowadays is, in fact, via a pipe outfall, so the siting of these outfalls in relation to waves, tides and currents is of paramount importance.

These systems discharge the pollutants a few kilometres from the coast, on the inner part of the continental shelf, in order to avoid the direct contamination of the inshore waters (e.g. beaches). Therefore, the implementation of a submarine outfall system requires a prior study: the characteristics of the outfall site have to be established in order to achieve optimal rates of dilution of the pollutants released into the environment.

A case study was conducted to analyse the behaviour of the pollutant cloud released at the São Jacinto (Aveiro, Portugal) submarine sewer outfall. This submarine outfall is located about $3 \mathrm{~km}$ offshore and $3 \mathrm{~km}$ north of the Barra channel (Ramos et al. [3]). The Barra channel is an artificial channel that connects the coastal lagoon (Ria de Aveiro) with the open ocean. This lagoon (Ria de Aveiro) and its surrounding coastal zones provide natural conditions for a harbour, and navigation and recreation facilities.
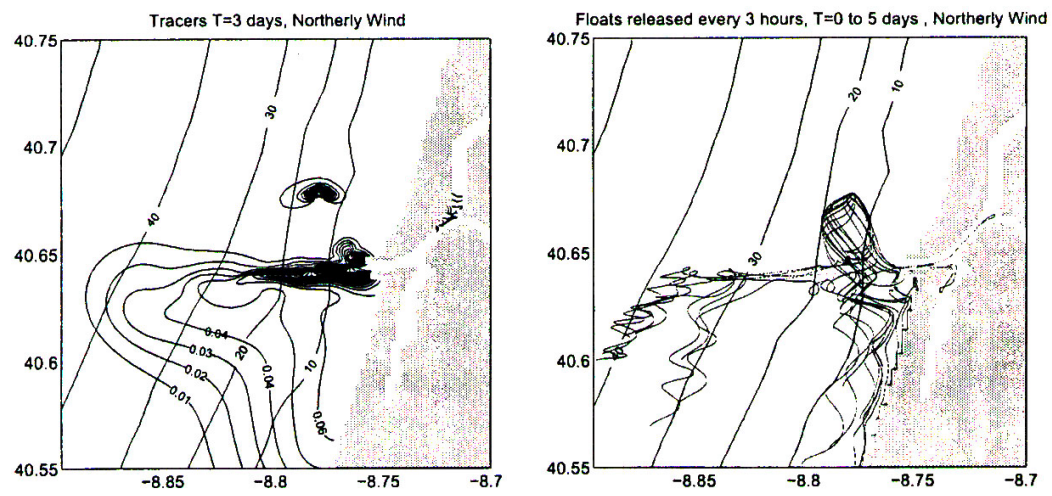

Figure 1: Northerly wind forcing: a) contour lines of tracer's concentration on the third day of simulation; b) the contour paths for the floats released at the submarine sewer outfall (Ramos et al. [3]). 
Numerical simulations were carried out on different wind regimes, as well as the influence of tide-induced currents in the region, close to the entrance of the lagoon, and their interaction with the cloud of pollutants released at the outfall.

Simulations were performed over a 14-day period. Considering a northerly wind forcing, as a representative example, Figure 1 shows that the maximum concentration values obtained with a northerly wind forcing are observed at the discharge point, and strong concentration decay occurs within a zone approximately $1 \mathrm{~km}$ from the point source, where the observed concentration is $0.01 \%$ of the injected value (Ramos et al. [3]).

This study has shown that, in all the situations tested, the polluted plume is diluted at a short distance from the source (at a scale of 1-2 km), and does not seem to interact with the Ria de Aveiro lagoon or with the coastal beaches.

\section{Estuaries and coastal bays}

Estuaries are biologically productive bodies of water. They are important as the spawning and nursery grounds for many coastal fish and invertebrates. Estuaries thus support commercial and recreational fishing and shellfish harvesting. Many are valuable locations for recreational boating and bathing, and are prized aesthetic resources. At the same time, many estuaries contain important harbours, ports, and navigation channels. A lot of the world's seaports are located on estuaries and ready access requires the maintenance of navigation channels (Martin and McCutcheon [6]).

Industries whose presence often increases the hazard to these fragile ecosystems also tend to locate in these seaports. Many estuaries flush municipal and industrial wastewater out to sea.

The economic, social and environmental conditions of various European estuarine systems have changed dramatically in recent decades as a consequence of anthropogenic effects, and they will go on changing in the years to come, thanks to increasing human pressure. New strategies are needed to develop a multifunctional use structure, which must take into account the many-faceted aims of sustainable development.

The various uses of an estuary place conflicting demands and burdens on water quality. To support this development, integrated analysis of new information sources is necessary. Furthermore, it should be possible to enact planning scenarios during the decision process, and for that we need to have instruments that will help decision-makers to find optimised solutions for existing problems. Mathematical models serve as an aid in assessing the effects of these conflicting demands and in developing protective management strategies.

Recent instruments introduced into European Union water policy by Water Framework Directive 2000/60/EC of the European Parliament and of the Council of 23 October 2000 create a coherent and comprehensive framework for the protection of all European Union coastal waters, through: $i$ ) an ecological and holistic water status assessment approach; ii) estuarine systems planning; iii) a strategy to eliminate pollution by dangerous substances; $i v$ ) public information 
and consultation, and $v$ ) financial instruments. The newly introduced concepts and regulations the directive establishes provide for the creation of an interface with users, the preparation of reports, and the collection of field information about water use proposals and hydrologic network changes.

In the meantime, as coastal waters are the end receiver of the pollution that is dumped into all bodies of fresh water, the good state of coastal waters only can be made an issue if it assumed that this is a global concern that should be studied in its integrity. This is well recognized in EU Directive 2000/60/EC, which establishes in point 17) of its grounds: "An effective and coherent water policy must take account of the vulnerability of aquatic ecosystems located near the coast and estuaries or in gulfs or relatively closed seas, as their equilibrium is strongly influenced by the quality of inland waters flowing into them. Protection of water status within river basins will provide economic benefits by contributing towards the protection of fish populations, including coastal fish populations".

Estuaries and enclosed lagoons or semi-enclosed bays have low acceptance capacities, due to the slow turnover of their water mass, while "more open" coastlines can assimilate higher volumes or concentrations without undue harm. In fact, the circulation of water is the major buffer to environmental stress imposed by sewage disposal.

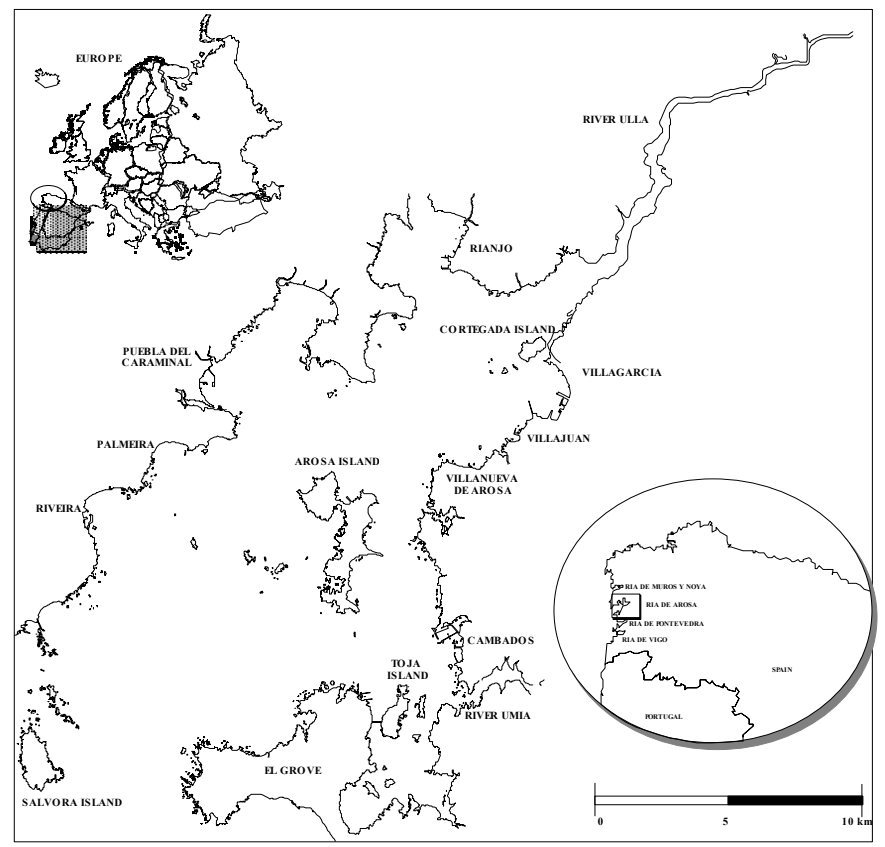

Figure 2: $\quad$ Location and general layout of Ria de Arosa (Pinho et al. [7]).

In general, coastal bays are very sensitive areas, being highly vulnerable to anthropogenic activities since their surrounding areas are intensively urbanized and their resources are frequently used in a way that implies several risks to their 
sustainability. This is the case of Ria de Arosa, which is the largest of the Rias Bajas on the north-western Galician-Spanish coast (Figure 2).

These coastal zones are ocean bays that support high shellfish production through intensive raft culture of the edible mussel Mytilus edulis, supported by the phenomenon of the intermittent upwelling of nutrient-rich deep waters. These coastal bays are also used both as the main receiving water bodies of wastewater produced in the coastal urban areas, and for recreational purposes and port activities. This bay has been studied in the past (Pinho et al. [7], Pinho et al. [8]).

This system involves ten drainage subsystems with final rejection, and serves an equivalent population of about 267000 inhabitants. To establish the water quality parameters' concentration limits for the Ria de Arosa, the following water uses have been identified: bathing and aquaculture. This last water use was further divided into zones of aquaculture banks and polygons of aquaculture rafts. Figure 3 shows a delimitation of the water uses and the location of the submarine outfalls (Pinho et al. [7]).

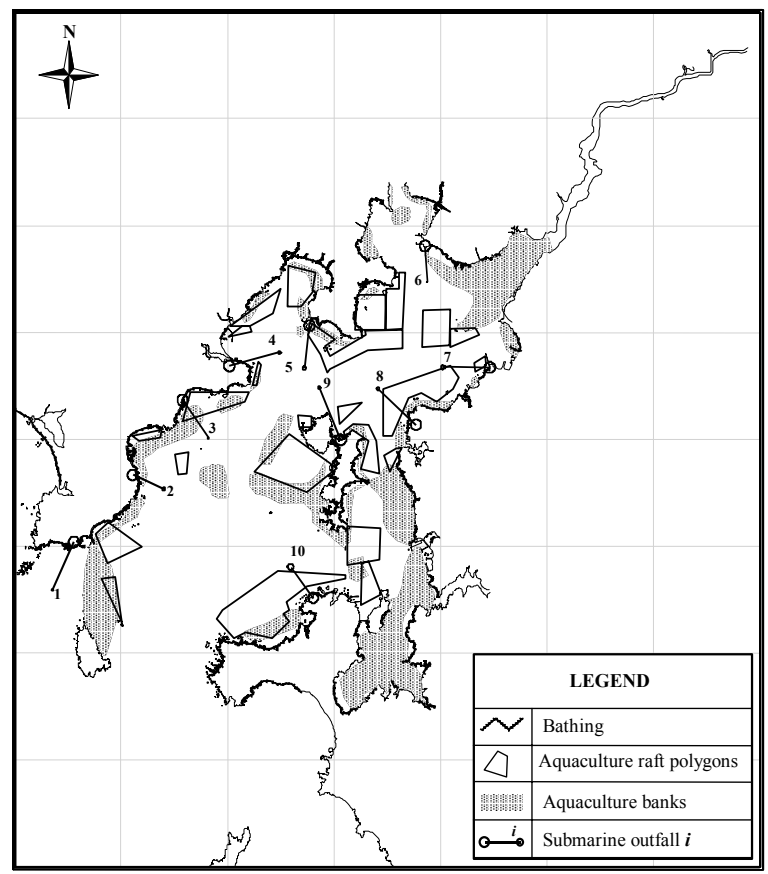

Figure 3: Figure 3: Delimitation of water uses in the Ria de Arosa, and location of the submarine outfalls (Pinho et al. [7]).

Different hypothetical scenarios for the temporal evolution of faecal matter concentration have been analysed, depending on: the turbulent diffusion coefficient concentration values, ranging from 10 and $50 \mathrm{~m}^{2} \mathrm{~s}^{-1}$; on the hydrodynamic conditions, namely the wastewater discharge, supposing that it could induce water current velocities with distinct vertical velocity components; 
on the primary treatment efficiency (faecal matter removal), and considering different values for the first order decay coefficient (5day ${ }^{-1}$ and $\left.10 d a y^{-1}\right)$ (Pinho et al. [7]).

Figure 4 shows the effect of different water column stratification conditions, and Figure 5 illustrates the effect of different Faecal Coliform bacteria (FC) decay coefficients in the plume characteristics.

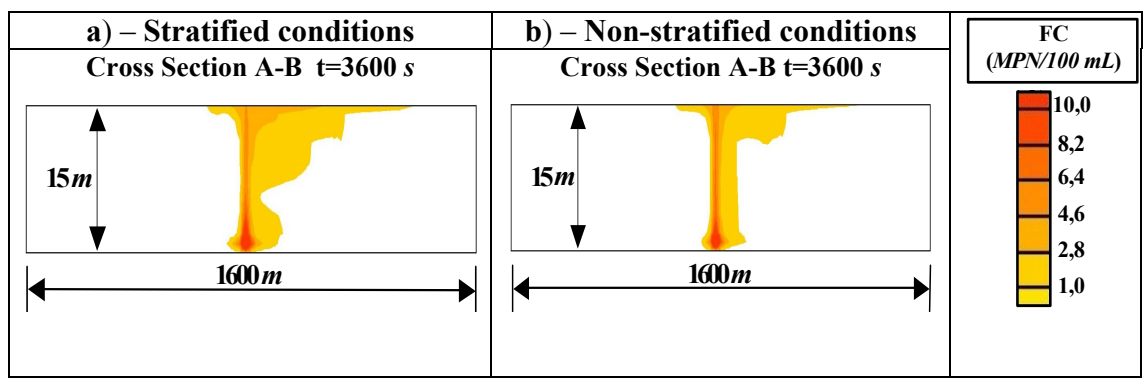

Figure 4: Villagarcia de Arosa submarine outfall model (7 in Figure 3): Numerical FC concentration results, considering different water column stratification conditions: a) stratified water column, b) homogeneous water column (Pinho et al. [7]).

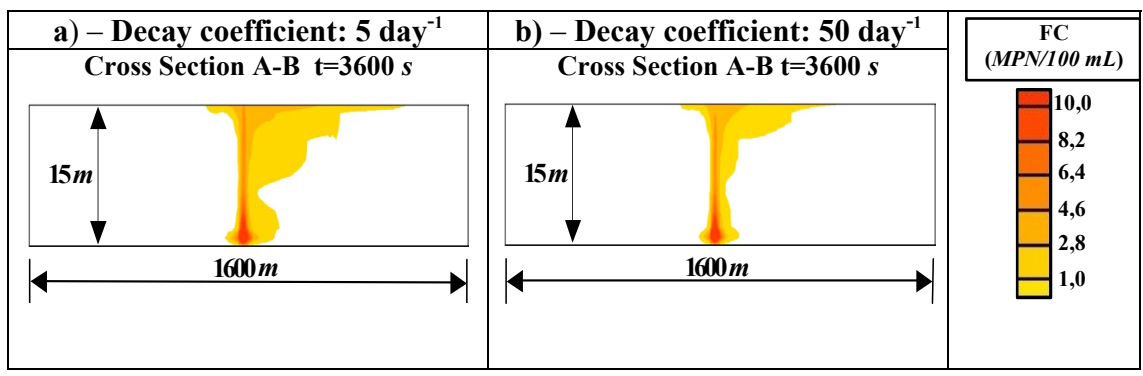

Figure 5: Villagarcia de Arosa submarine outfall model (7 in Figure 3): Numerical FC concentration results, considering different FC decay coefficients: a) $5 d a y^{-1}$; b) $50 d a y^{-1}$ (Pinho et al. [7]).

The studies conducted on this rich and productive ecosystem have shown that wastewater plume characteristics and behaviour depend either on the receiving waters' ambient conditions (water body geometry, current patterns and water column stratification) and on discharge characteristics (submarine outfall diffusers' geometry, wastewater discharge, near-field velocity and wastewater density). 


\section{Conclusions}

The pollution of rivers and streams by chemical contaminants became one of the most crucial environmental problems of the $20^{\text {th }}$ century. Waterborne chemical pollution entering rivers and streams causes tremendous destruction. Comprising over $70 \%$ of the Earth's surface, water is undoubtedly the most precious natural resource that exists on our planet as it is essential for everything to grow and prosper. Although we as humans recognize this fact, we disregard it by polluting our rivers, lakes, and oceans. We are therefore, slowly but surely, harming our planet to the point where organisms are dying at a very alarming rate.

This paper is intended as a contribution to the preservation of coastal zones in a context in which a great deal of pollution is released into the sea, either directly or through submarine outfalls.

To be as efficient as possible, and to avoid aggravating the weakness of existing environmental conditions, the design and construction of submarine outfalls should take into account the geometry of the water body and the dynamic conditions (receiving water currents and density distribution in the water column). Also of great significance are the mixture conditions, the geometry and type of the submarine outfall diffusers, the residual water discharge, the water velocity at the submarine outfall diffusers and the wastewater density.

\section{References}

[1] Carter, R.W.G., 1993. Coastal environments: An introduction to the physical, ecological and cultural systems of coastline, Academic Press Limited, ISBN 0-12-161855-2.

[2] Jirka G.H., Doneker R.L. \& Hinton S.W., 1996. User's Manual for CORMIX: a Hydrodynamic Mixing Zone Model and Decision Support System for Pollutant Discharges into Surface Waters, DeFrees Hydraulics Laboratory, School of Civil and Environmental Engineering, Cornell University, New York.

[3] Ramos M., Almeida M., Silva P., Dubert J. \& Antunes do Carmo J.S., 2003. "Modelling study of the dispersion of pollutants at São Jacinto submarine outfall (Aveiro, Portugal)." Proc. Coastal Engineering Conference, Cadiz Spain, 23 - 25 June. Published in Coastal Engineering VI, 133 -141, Ed. WITPRESS, ISBN 1-85312-977-1.

[4] Song, Y. \& Haidvogel, D.B., 1994. "A semi-implicit ocean circulation model using generalized topography following coordinate system." J. Comp. Phys., 115, pp. 228-244.

[5] Pinho J.L.S., 2001. Mathematical modelling application to hydrodynamics and water quality studies of coastal zones. PhD Thesis, University of Minho, Portugal. (in Portuguese).

[6] Martin J.L. \& McCutcheon S.C., 1999. Hydrodynamics and transport for water quality modelling, Lewis publishers, ISBN 0-87371-612-4. 
24 Water Pollution VIII: Modelling, Monitoring and Management

[7] Pinho J.L.S., Vieira J.M.P. \& Antunes do Carmo J.S., 2002. “Application of a 3D model for submarine outfalls environmental impact assessment. A Case Study." Proc. IWA $-3^{\text {rd }}$ Water World Congress, Melbourne, Australia, April.

[8] Pinho J.L.S., Vieira J.M.P. \& Antunes do Carmo J.S., 2001. "Hydrodynamics and water quality studies in Ria de Arosa applying mathematical modelling." Proc. Oceans III Millennium, $1^{\text {st }}$ International Congress on Marine Science and Technology, Pontevedra (Galicia) - Spain, 24 - 27 April. 